Working Paper 9608

\title{
U.S. INTERVENTION: ASSESSING THE PROBABILITY OF SUCCESS
}

by Owen F. Humpage

Owen F. Humpage is an economic advisor at the Federal Reserve Bank of Cleveland. For helpful suggestions, the author thanks Catherine Bonser-Neal, Charles Goodhart, Yoon Dai Kim, Carol Osler, Allan Malz, and participants at both the Federal Reserve System Committee on International Economic Analysis and the University of Kentucky Macro Seminar. Sandy Sterk provided valuable technical assistance.

Working papers of the Federal Reserve Bank of Cleveland are preliminary materials circulated to stimulate discussion and critical comment. The views stated herein are those of the author and not necessarily those of the Federal Reserve Bank of Cleveland or of the Board of Governors of the Federal Reserve System.

Working papers are now available electronically through the Cleveland Fed's home page on the World Wide Web:

http://www.clev.frb.org.

September 1996 


\begin{abstract}
This paper estimates the unconditional and conditional probabilities that U.S. interventions successfully smooth short-term mark-dollar and yen-dollar exchange rates. The sample period extends from February 1987 to February 1990. Assuming a binomial distribution, the number of observed successes usually is greater than one would expect to see randomly. Results from a logit model suggest that coordinated intervention has a higher probability of success than unilateral intervention. The probability of success also increases with the dollar amount of an intervention. Other conditioning variables are not significant. The paper presents a reaction function, with adjustments for the incidentally truncated nature of intervention data. Predicted values serve as instruments for intervention in the logit models.
\end{abstract}




\section{Introduction}

Over the last 23 years of generalized floating, the United States has periodically bought and sold foreign reserves in an effort to influence exchange rates. Economists have questioned the efficacy of U.S. intervention because the Federal Reserve System routinely sterilizes its impact on the monetary base. Although the process of sterilizing intervention alters the currency composition of outstanding government securities, thereby offering a second possible channel of influence, studies provide no compelling evidence of significant portfolio-adjustment effects (see Edison [1993]).

Instead, empirical research generally finds neither strong nor consistent correlations between official interventions and changes in either exchange rates, exchange-rate risk premia, or measures of exchange-rate volatility. ${ }^{1}$ Results usually are not robust across time periods, currencies, or model specifications, suggesting that success might depend solely on the ability of intervention to affect market expectations. Most economists regard exchange markets as highly efficient, but information is costly, and some interval must pass between the receipt of new information and its full incorporation into foreign exchange quotations. That monetary authorities might sometimes possess an information advantage seems possible, but whether they do so routinely and can regularly exploit this advantage in pursuit of exchange-rate objectives is questionable.

As a means of studying the expectations channel, this paper estimates the conditional and unconditional probabilities with which U.S. intervention might smooth exchange-rate movements. A high probability of success implies that intervention regularly affects expectations that underpin foreign exchange quotes. Conditioning these probabilities indicates which aspects of intervention increase the chances of

1 Dominguez and Frankel (1993) and Ghosh (1992) are possible exceptions. Edison (1993) surveys the literature. See Bonser-Neal and Tanner (forthcoming) for recent evidence on measures of volatility. 
success. My sample includes official U.S. intervention data at a daily frequency from February 1987 to February 1990. This was a period of frequent and heavy U.S. intervention--often conducted in concert with Germany and Japan--to stabilize dollar exchange rates "at current levels" (see Funabashi [1988]).

Section I defines success in terms of a smoothing criterion, counts the number of successful interventions, and compares that count to the expected number of successes based on a binomial distribution. The approach adopted here avoids ambiguities inherent in regression analysis. In a regression of exchange-rate changes on intervention, for example, a positive coefficient may imply a perverse response--foreign exchange purchases (sales) cause dollar appreciations (depreciations)--or it may imply that intervention smoothes exchange-rate movements without reversing them. ${ }^{2}$ In section I, I find that with one exception (U.S. purchases of German marks), the probability of observing a greater number of successes than actually occurred is relatively small, suggesting that intervention affects exchange rates.

Section II asks whether various techniques for intervention improve the chances of success. I model the conditional probability of success using the logistic probability distribution and conditioning variables suggested by other studies. The results indicate that central banks can significantly increase the odds of success by coordinating their interventions. The dollar amount of intervention is also significant, but it is of secondary importance to coordination. Other conditioning variables, notably the oftmentioned distinction between reported and unreported intervention, seem unimportant (see Dominguez and Frankel [1993]). Section III derives conditional probabilities of

2 Similarly, studies of the portfolio-adjustment channel typically define the risk premium as unexploited profits from an uncovered parity condition. Then, by assuming that interest rates and the expected future spot exchange rate are exogenous, they infer that correlations between intervention and the risk premia solely represent a relationship between intervention and the spot exchange rate. This need not be the case. 
success from estimated logit models, and the final section concludes with some policy implications.

An appendix describes the use of censored regression techniques employed in constructing reaction functions for intervention. The predicted values from these functions serve as instruments for intervention in the logit models. Failure to account for the joint determination of exchange-rate changes and intervention can bias parameter estimates.

\section{Smoothing Exchange-Rate Movements}

The Federal Reserve Bank of New York, as agent for both the U.S. Treasury and the Federal Open Market Committee (FOMC), intervenes to "counter disorderly markets."3 In practice, Treasury and Federal Reserve officials determine market disorder subjectively, relying on a mutable set of macroeconomic and financial criteria (see Smith and Madigan [1988]). As a result, notions of success are similarly inconstant and subjective, and unlike the criterion presented below, may not bear a one-to-one relationship with individual interventions.

This paper defines success in terms of smoothing exchange-rate movements. This criterion is compatible with many definitions of calming market disorder and with the G7's Louvre objective of stabilizing dollar exchange rates "at current levels." Moreover, empirical estimates of intervention reaction functions report evidence of a smoothing objective (see Almekinders and Eijffinger [1991, 1992] and Edison [1993]).

Accordingly, I define the following dichotomous success criterion:

3 Paragraph 1 of the FOMC's Foreign Currency Directive states: "System operations in foreign currencies shall generally be directed at countering disorderly market conditions, provided that market exchange rates for the U.S. dollar reflect actions and behavior consistent with the IMF Article IV, Section 1." 


$$
w_{t}=\left\{\begin{array}{l}
1\left\{\begin{array}{l}
\text { if } I_{t}>0 \text { and } \Delta S_{t}>0, \text { or } \Delta S_{t}>\Delta S A M_{t}, \text { or } \\
\text { if } I_{t}<0 \text { and } \Delta S_{t}<0, \text { or } \Delta S_{t}<\Delta S A M_{t} ;
\end{array}\right. \\
0 \begin{array}{l}
\text { otherwise }
\end{array}
\end{array}\right.
$$

In this expression, $I_{t}$ designates official intervention at time $t$, with positive (negative) values being sales (purchases) of foreign exchange; $\Delta S_{t}=S P M_{t}-S A M_{t}$, where $S A M$ and $S P M$ are, respectively, New York morning and afternoon bid quotations expressed as foreign currency units per dollar; and $\Delta S A M_{t}=S A M_{t}-S A M_{t-1}$. The Federal Reserve Bank of New York obtains these quotations from surveys of dealers conducted at 9:00 a.m. and 4:00 p.m., respectively. Nearly all U.S. intervention occurs between these times, typically while European markets are still open (see Goodhart and Hesse [1993]). The intervention data do not include purchases and sales that the Federal Reserve undertakes for official customers and with no intent to influence exchange rates (see Adams and Henderson [1983]).

As expression (1) indicates, $w_{t}$ equals one--implying success--if intervention sales (purchases) of foreign exchange are associated with a dollar appreciation (depreciation) on day $t\left(\Delta S_{t}\right)$, or if they are associated with a smaller dollar depreciation (appreciation) when comparing $\Delta S_{t}$ with $\triangle S A M_{t}{ }^{4}$

The Federal Reserve Bank of New York undertakes nearly all of its intervention in the U.S. market. During our sample period, every intervention was against German marks or Japanese yen. Table 1 presents summary statistics for these interventions. Figure 1 compares U.S. intervention against marks with mark-dollar exchange-rate movements, while figure 2 compares U.S. intervention against the yen with the yendollar rate.

Table 2 counts the total number of interventions, $n$ (column \#1), and the number of successful interventions, $W$ (column \#2), over our sample period. Approximately 64

4 Notice that this criterion accommodates intervention that leans with the wind. The United States has sometimes intervened to reinforce exchange-rate movements, as after the Plaza Accord in September 1995. 
percent of all U.S. interventions against German marks and nearly 75 percent of all U.S. interventions against Japanese yen successfully smoothed exchange-rate movements. Sales of marks or yen were more frequently successful than purchases of these currencies.

I want to determine, however, if the number of successes is large, since a high number of successes could result from the natural martingale behavior of spot exchange rates even if intervention were ineffective. Under a martingale process, day-to-day exchange-rate changes have an expected value of zero, with equal probability of appreciation or depreciation. Consequently, having observed a depreciation on day $t$, the probability of finding a smaller depreciation on day $t+1$ is greater than 50 percent.

The dichotomous variable, $w_{t}$, has a Bernoulli distribution with the $\operatorname{Prob}\left[w_{t}=1\right]=p$. The number of successes in $n$ independent trials, $W=\sum_{i=1}^{n} w_{i}$, has a binomial distribution, with $\mathrm{E}(W)=n p$ and $\operatorname{Var}(W)=n p(1-p) .{ }^{5}$

I estimate $p$ for both intervention purchases and intervention sales following two procedures. First, I calculate $\hat{p}_{1}$ (column \#4 of table 2) as the number of times smoothing naturally occurred on sample days when the Federal Reserve did not intervene. I excluded U.S. intervention days to avoid possible influences from intervention. For the German mark, there were 616 such trials, and for the Japanese yen, 625 trials (column \#3). I counted as smoothing 1) the number of appreciations in $\Delta S_{t}$ plus the number of smaller depreciations when comparing $\Delta S_{t}$ with $\triangle S A M_{t}$, and 2) the number of depreciations in $\Delta S_{t}$ plus the number of smaller appreciations when comparing $\triangle S_{t}$ with $\triangle S A M_{t}$.

\footnotetext{
5 The success criteria consider only a count of success. The mean absolute value of exchange-rate changes--both for German marks and Japanese yen--are significantly larger on days of U.S. intervention than on days of no U.S. intervention.
} 
Based on these probabilities ( $\hat{p}_{1}$ 's), one might expect to observe 23 successful U.S. sales of German marks, 71 successful U.S. purchases of German marks, 42 successful sales of Japanese yen, and 44 successful purchases of Japanese yen even if the Federal Reserve acted randomly and if intervention were completely ineffective. Column \#6, however, suggests that the probability of randomly observing a greater number of successes than was actually found is fairly low in every case except that of U.S. purchases of German marks. ${ }^{6}$

An underlying assumption in these calculations is that smoothing movements in exchange rates are independent events. A substantial body of evidence suggests that exchange rates follow a martingale process with heteroskedastic error terms. ${ }^{7}$ The summary data in table 3 confirm this pattern for our sample. Martingales do some damage to the assumption of independent trials, but the offending temporal dependence appears only in higher moments of the exchange-rate process. Moreover, official intervention could create persistence in the variance. The statistic for biasness in our sample $\left(\mathrm{m}_{3}\right)$ is sometimes significant, but its significance often seems sensitive to whether the sample includes intervention. (The restricted sample in table 3 excludes interventions.) The significant kurtosis $\left(\mathrm{m}_{4}\right)$ in our sample is consistent with GARCH effects and a martingale process.

6 The differences between U.S. intervention against German marks and Japanese yen could result from the fact that U.S. intervention was often coordinated with Germany and Japan over this period, and because Japanese intervention was associated with innovations in money growth, which markets might then anticipate (see Watanabe [1994]). Germany usually tends to sterilize (see Neumann and von Hagen [1991]).

7 A martingale process implies that the expected exchange-rate change is zero and that the probability of an appreciation or depreciation is equal (i.e., exchange-rate changes are not biased). A martingale process also implies that exchange-rate changes are not serially correlated, but unlike the random-walk hypothesis, it does not require exchangerate changes to be independent and identically distributed. Exchange-rate changes typically exhibit extreme kurtosis. Baillie and McMahon (1989) provide a detailed discussion of the statistical properties of exchange-rate changes. 
As a further test, I calculate the probability of observing an individual success, $\hat{p}_{2}$, as the frequency of observing smoothing in 1,000 replications of artificial randomwalk exchange-rate processes. I construct the series using the calculated second moments for the German mark and Japanese yen exchange rates. Each replication consists of 616 observations for the mark and 625 observations for the yen.

Using the $\hat{p}_{2}$ ' (table 2, column \#5), one might expect to observe 22 successful U.S. sales of German marks, 67 successful U.S. purchases of German marks, 40 successful sales of Japanese yen, and 44 successful purchases of Japanese yen even if the Federal Reserve acted randomly and if intervention were completely ineffective. Column \#7, however, shows that the probability of randomly observing a greater number of successes than was actually found is less that 5 percent in every case except that of U.S. purchases of German marks.

These results confirm the earlier finding: Successful intervention is not a random event attributable to the martingale nature of exchange rates. U.S. intervention appears to affect information important to the pricing of foreign exchange.

\section{The Odds of Successful Intervention}

The United States might improve its chances for success by conducting intervention in a specific manner or by associating it with other events. I model the conditional probability of success using the logistic cumulative density function:

$$
P_{i}\left(w_{i}=1 \mid \mathbf{X}_{\mathbf{i}}\right)=\frac{1}{1+\exp \left(-w_{i}\right)},
$$

where $w_{i}(i=1, \ldots, n)$ is the dichotomous success variable described in expression (1). ${ }^{8} \mathrm{I}$ hypothesize that success is a linear function of explanatory variables:

$8 W=\sum_{t=1}^{T} w_{t}=\sum_{i=1}^{n} w_{i}$. I estimate the logit model only over observations containing intervention. 


$$
w_{i}=\mathbf{X}_{\mathbf{i}} \mathbf{b},
$$

where $\mathbf{X}_{\mathrm{i}}$ is a $(1 \times \mathrm{K})$ vector of variables that influence the probability that intervention will be successful, and $\mathbf{b}$ is a $(\mathrm{K} \times 1)$ column vector of parameters.

The logit function is the log of the odds ratio, which I estimate using maximumlikelihood techniques:

$$
\hat{L}_{i}=\ln \left(\frac{\hat{P}_{i}}{1-\hat{P}_{i}}\right)=\mathbf{X}_{\mathbf{i}} \hat{\mathbf{b}}+u_{i},
$$

where $\hat{P}_{i}$ is the estimated relative frequency of observing $w_{i}=1$ in $n$ trials, and where the variance of $u_{i}$ equals $1 /\left[n_{i} P_{i}\left(1-P_{i}\right)\right]$ (see Judge et al. [1988], pp. 788-95).

Included in the conditioning vectors are those variables frequently suggested in the literature as influencing the likelihood of successful intervention. Before presenting the estimates, I discuss the conditioning variables.

\section{Dollar Amount of Intervention}

Within the context of the portfolio-adjustment theory of exchange-rate determination, the amount of an intervention seems crucial, since the exchange-rate response is a function of the relative change in outstanding government debt. Within the context of an expectations channel, the importance of the amount of intervention is unclear. Large interventions need not have a substantially greater effect on market expectations than small interventions. The Federal Reserve Bank of New York often undertakes interventions with many commercial banks at different times during the day. At any point during the day, individual traders, while aware that the Fed is in the market, may be unaware of the total amounts. Indicative of this, amounts reported in news accounts of intervention are often vague or incorrect (see Osterberg and Wetmore Humes [1993]).

Three measurements attempt to assess the importance of the amount of intervention. First, I consider the absolute value of the dollar amount of U.S. intervention against German marks (ING) and Japanese yen (INJ). Because intervention 
and exchange-rate movements are jointly determined, estimated coefficients for these variables are likely to be biased. Consequently, I also use as instruments the predicted values of intervention from an appropriately identified reaction function. These are IHATG and IHATJ for intervention against marks and yen, respectively. (The appendix discusses the sample selection technique used to estimate IHATG and IHATJ.)

As a further test of the importance of an intervention's size, I construct dummy variables for large interventions. BG1 and BJ1 equal one when U.S. interventions against German marks and Japanese yen are at least one standard deviation above the mean absolute amount of intervention, as recorded in table 1. Special Factors Affecting Expectations

Empirical investigations by Loopesko (1984) and Dominguez (1990) suggest that coordinated central-bank intervention significantly affects exchange rates more often than does uncoordinated intervention. Coordinated intervention could affect expectations more profoundly than unilateral actions if it shows agreement among central banks about the nature of the information in the market.

Accordingly, the dummy variables, CORDG and CORDJ, equal one, respectively, when the United States and Germany, and the United States and Japan, intervene in concert. I constructed CORDG from official German intervention data, and CORDJ from published references to Japanese intervention. ${ }^{9}$ The sample includes 114 coordinated interventions with Germany and 102 coordinated interventions with Japan.

Intervention often occurs over a string of days, with long intermittent periods of no intervention. Humpage (1988) found that the first intervention in a string was more apt to be significantly correlated with exchange-rate changes than were the subsequent interventions in a series. Subsequent interventions may not provide new information.

9 The Bundesbank provided us with official German intervention data. The Bank of Japan keeps intervention data confidential. 
As a further check, I tested a dummy variable, FRST, that equals one when U.S. intervention against a specific currency is the first in the past five business days.

The New York Fed's Foreign Exchange Desk can intervene directly with commercial banks, or it can operate through the broker's market. The latter method affords the System anonymity; the former does not. ${ }^{10}$ Dominguez and Frankel (1993) contend that known intervention--proxied by newspaper accounts--affects exchange rates more often and more strongly than does secret intervention. Hung (1992) disagrees, saying that the importance of anonymity depends on the nature of the information. Osterberg and Wetmore Humes (1993) question the accuracy of news accounts.

I consider three dummy variables that measure reported interventions: 1) RI equals one when The Wall Street Journal reports any intervention activity against the dollar whatsoever, 2) RIA equals one when The Wall Street Journal specifically refers to U.S. intervention, and 3) REPINT is the dummy variable for reported intervention found in Dominguez and Frankel (1993).

\section{Monetary Policy}

The Federal Reserve routinely sterilizes U.S. intervention in the sense of not allowing an intervention to interfere with the attainment of its reserve or federal funds rate targets. Nevertheless, unexpected changes in monetary policies can affect exchange rates, and interventions that coincide with them will appear more successful than they otherwise would.

During the sample period, the FOMC set its federal funds rate target (FTAR) to be consistent with the degree of reserve pressure that it desired at a particular time.

${ }^{10}$ When the Federal Reserve deals directly with a commercial bank, that bank is free to announce that the Fed is in the market. When the Fed enters the broker's market, it gets a commercial bank to act as its agent. The broker knows and reveals only the identities of the commercial banks that are party to the transactions. The agent bank must keep the Fed's transaction secret. 
Often, the FOMC altered FTAR in a policy move to affect the markets, but sometimes it adjusted the target in response to gradual shifts in underlying market pressures. Generally, following Sellon (1994), I construct an effective federal funds rate target, EFTAR, that attempts to measure only discretionary policies designed to operate on the economy. In constructing EFTAR, I do not incorporate changes in the borrowing assumptions that the FOMC undertook for such technical factors as seasonal borrowing, special situation borrowing, or shifts in the discount spread. Moreover, I do not relate the changes in the borrowing assumption to the changes in EFTAR strictly according to Sellon's rule, but sometimes deviate if changes in FTAR suggest a different pattern. ${ }^{11}$

FTAR and EFTAR measure policy changes in basis points, typically $12.5,25$, or 50 (see figure 3). I also measure monetary policy changes with dummy variables: T1 equals one when FTAR changes, and T2 equals one when EFTAR changes. For similar reasons, I also include a variable for changes in German and Japanese monetary policies. GMP equals one whenever the German Lombard, discount, or repurchase rate changes; JMP equals one when either the official Japanese discount rate or the overnight bank rate changes.

Sterilized intervention that is inconsistent with the thrust of monetary policy could have a substantially different effect on exchange rates than intervention that is consistent with monetary policy. The dummy variable YES equals one if the United States bought (sold) foreign exchange when the FOMC was lowering (raising) EFTAR. Other Events

Just as contemporaneous changes in monetary policy may result in successful intervention, coincidental reports of other events might increase the chances for success.

11 Sellon equates every $\$ 100$ million change in the nonborrowed reserve path to a 25 basis-point change in the effective funds rate target, and allows changes in the discount rate to lead to an equal change in the effective funds rate target (see Sellon [1994], pp. 12-13). 
We include the dummy variables CPI, EMP, BOT, and GNP, which equal one, respectively, on the release days for consumer prices, the unemployment rate, the monthly balance of trade, and quarterly GNP. We also include UXCPI, UXEMP, UXBOT, and UXGNP, which measure differences between the actual and the expected values of these economic indicators on their release dates. The expected values are the median expectations from the Money Market Services surveys of expectations. NEWS, also from Dominguez and Frankel (1993), is a catch-all dummy variable for other policy events that might provide information to the market.

Results

Table 4 (U.S. interventions against German marks) and table 5 (U.S. interventions against Japanese yen) present the results from estimating the logit function with each of the explanatory variables included separately. The odds that U.S. intervention will successfully smooth exchange-rate movements significantly increase with the amount of intervention (after adjusting for simultaneity) and when intervention is coordinated. For U.S. intervention against German marks, IHATG is significant at the 95 percent confidence level, and CORDG is significant at the 90 percent interval. For U.S. intervention against Japanese yen, IHATJ is significant at the 90 percent confidence level, and CORDJ is significant at the 95 percent level. None of the other explanatory variables seems to affect the odds ratio significantly.

We next consider the joint significance of the explanatory variables (tables 6 and 7) by adding combinations of other variables to CORDG and CORDJ. The first row of table 6, for example, shows the log likelihood and the likelihood-ratio test of CORDG. Adding IHATG to CORDG significantly improves the fit, according to the likelihoodratio test in column 3. CORDG and IHATG are jointly significant at the 95 percent confidence level, according to the likelihood-ratio test in column 2. Adding T2 to CORDG similarly improves the fit. Although FRST and CORDG, and REPINT and CORDG, are jointly significant at the 95 and 90 percent levels, respectively, all of the 
explanatory power is in CORDG, since adding either FRST or REPINT does not improve the fit.

I proceed by adding individual variables to CORDG and IHATG. Although nearly all are jointly significant at the 95 percent confidence level, the explanatory power comes solely from IHATG and CORDG. T2 and REPINT no longer seem to

contribute to the fit. Table 6 continues to build in a similar manner, but with no additional results.

The procedure in table 7 parallels that in table 6. Overall, only coordination and the amount of intervention seem capable of predicting the success of intervention. ${ }^{12}$

\section{Conditional Probabilities of Success}

Rearranging equation (4) gives the conditional probability of success as

$$
P_{i}\left(\mathbf{X}_{\mathbf{i}} \mathbf{b}\right)=\frac{e^{\mathbf{x b}}}{1+e^{\mathbf{x b}}} .
$$

Table 8 shows estimates of the conditional probability of success for U.S. intervention against German marks. The first column presents estimates of the conditional probabilities when equation (5) is evaluated using the logit equation that includes only CORDG:

$$
\begin{array}{cll}
\hat{L}=0.095+0.687(\mathrm{CORDG}) ; & L L=-92.514 ; \\
(0.31) \quad(1.83) & L L(0)=-94.184 .
\end{array}
$$

By coordinating its intervention against German marks with the Bundesbank, the United States increases the probability of success from 0.524 to 0.686 . Coordination seems crucial, given that we expect to observe random smoothing, as a result of the

12 Collinearity between the intervention terms and the coordination dummies is not a problem for U.S. intervention against German marks or Japanese yen. Neither term is significant in a regression (OLS or logit, as required) of one on the other. 
martingale nature of exchange rates, in approximately 62 to 65 percent of the observations.

I next evaluate (5) using a logit equation that includes CORDG and IHATG:

$$
\begin{aligned}
& \hat{L}_{i}=-1.694+0.794(\text { CORDG })+0.019(\text { IHATG }) ; \quad L L=-83.11 ; \\
& \text { (-3.06) (1.97) } \\
& L L(0)=-94.18 \text {. }
\end{aligned}
$$

Table 8 presents conditional probabilities evaluated at the mean value of IHATG and for the mean plus or minus one standard deviation. The amount of an intervention seems to increase the probability of success above what one might expect to observe randomly only when it is also coordinated, or when it is uncoordinated but very large (mean plus one standard deviation). At one standard deviation above the mean, the probability of success is 73 percent in the absence of coordination. The final column of table 8 presents the change in the probability of success (evaluated at the mean) for a marginal change in IHATG. The effect is minuscule.

Table 9 shows estimates of the conditional probability of success for U.S. intervention against Japanese yen. The first column presents estimates of the conditional probabilities when equation (5) is evaluated using the logit equation that includes only CORDJ:

$$
\begin{array}{cll}
\hat{L}=0.095+1.226(\mathrm{CORDJ}) ; & L L=-73.203 \\
(0.22) & (2.48) & L L(0)=-76.189
\end{array}
$$

By coordinating its intervention against the yen with the Bank of Japan, the United States increases the probability of success from 0.524 to 0.789 . Coordination seems crucial for success, given that we expect to observe random smoothing in approximately 62 percent to 66 percent of the observations without interventions.

I next evaluate (5) using a logit equation that includes CORDJ and IHATJ:

$$
\begin{array}{ccl}
\hat{L}=-0.307+1.182(\mathrm{CORDJ})+0.005(\mathrm{IHATJ}) ; & L L=-71.611 \\
(-0.62) & (2.37) & (1.70)
\end{array}
$$


Table 9 presents conditional probabilities evaluated at the mean value of IHATJ and the mean plus or minus one standard deviation. The amount of an intervention seems to increase the probability of success above what one might expect to observe if intervention were ineffective and undertaken randomly only when it is also coordinated. Even at one standard deviation above the mean, the probability of success is only 64 percent in the absence of coordination. The final column of table 9 presents the change in the probability of success (evaluated at the mean) given a marginal change in IHATJ. The effect is very small and independent of coordination.

\section{Conclusions}

Most economists accept that U.S. monetary authorities may sometimes possess an information advantage over the foreign exchange market, but question whether they can use it to pursue an exchange-rate objective. My results suggest that U.S. intervention frequently conveys information important to the pricing of foreign exchange. Over the sample period, I find that the observed number of successful interventions usually are greater than one would expect to uncover under a martingale exchange-rate process, if interventions were ineffectual and random.

Coordinating intervention significantly increases the chances of success. Other things equal, uncoordinated intervention has only about a 50 percent chance of being successful. The size of an intervention also affects its probability of success, but coordination is generally a better predictor. Interventions typically must approximate one standard deviation above their mean value to affect success in the absence of coordination, but central banks can achieve a similar probability of success at a much lower dollar amount of intervention through coordination. Other distinctions, such as between reported and unreported intervention or between first and subsequent interventions, have no impact on the likelihood of success. 
Two policy recommendations stem from these findings: 1) Central banks should coordinate their interventions, and 2) Maintaining a large portfolio of foreign exchange to facilitate frequent and large interventions seems unnecessary. 
Table 1: U.S. Intervention: Basic Statistics (millions of dollars)

\begin{tabular}{|c|c|c|c|c|c|c|}
\hline & \multicolumn{3}{|c|}{ Against yen } & \multicolumn{3}{|c|}{$\underline{\text { Against marks }}$} \\
\hline & Purchases & Sales & $\begin{array}{c}\text { Absolute } \\
\text { Value }\end{array}$ & Purchases & Sales & $\begin{array}{c}\text { Absolute } \\
\text { Value }\end{array}$ \\
\hline Mean & 162.3 & 138.2 & 150.9 & 156.1 & 122.4 & 147.7 \\
\hline Median & 130.0 & 100.0 & 120.0 & 100.0 & 80.0 & 100.0 \\
\hline Std. Dev. & 115.4 & 135.0 & 125.2 & 117.3 & 105.3 & 115.0 \\
\hline Minimum & 6.0 & 3.0 & 3.0 & 25.0 & 15.0 & 15.0 \\
\hline Maximum & 555.0 & 720.2 & 720.2 & 695.0 & 395.0 & 695.0 \\
\hline
\end{tabular}

Source: All tables are author's calculations. 
Table 2:

Success Criterion: Smoothing Movements in the Targeted Exchange Rate (February 18, 1987 to February 23, 1990)

\begin{tabular}{lrrrrrrr} 
& $\# 1$ & $\# 2$ & $\# 3$ & $\# 4$ & $\# 5$ & $\# 6$ & $\# 7$ \\
\hline & & & & & & & \\
$\begin{array}{l}\text { German Marks } \\
\text { Sales }\end{array}$ & & & & & & & \\
Purchases & 108 & 27 & 616 & 0.65 & 0.62 & 0.07 & 0.04 \\
& 65 & 616 & 0.65 & 0.62 & 0.85 & 0.65 \\
Japanese Yen & & & & & & & \\
Sales & 64 & 50 & 625 & 0.66 & 0.62 & 0.01 & $<0.01$ \\
Purchases & 71 & 51 & 625 & 0.63 & 0.62 & 0.04 & 0.04
\end{tabular}

\section{Column:}

\#1: Official interventions in full sample, $n$.

\#2: Success: $W=\sum_{i=1}^{T} w_{t}=\sum_{i=1}^{n} w_{i}$, where $T=760$ observations in full sample. One can count success over the entire sample or over interventions.

\#3: Observations excluding interventions, $T-n$.

\#4: $\hat{p}_{1}=S_{1} /(T-n)$, where $S_{1}$ is the number of times smoothing is observed in $T-n$. In the rows marked sales: $S_{1}$ is the number of appreciations in $\Delta S_{t}$ plus the number of smaller depreciations when comparing $\Delta S_{t}$ with $\triangle S A M_{t}$, for all observations excluding interventions. In the rows marked purchases: $S_{1}$ is the number of depreciations in $\Delta S_{t}$ plus the number of smaller appreciations when comparing $\Delta S_{t}$ with $\triangle S A M_{t}$, for all observations excluding interventions.

\#5: $\hat{p}_{2}$ is the average frequency of observing smoothing in 1,000 replications of an artificial random-walk process, using the first and second moments for either the German mark or Japanese yen (see table 3). Each replication consists of 616 observations for the mark and 625 observations for the yen. Smoothing is as defined in \#4.

\#6: Probability of observing a greater number of successes than was actually observed (column \#2) in a sample equal to the number of interventions (column \#1), using $\hat{p}_{1}$ as the probability of an individual success.

\#7: Probability of observing a greater number of successes than was actually observed (column \#2) in a sample equal to the number of interventions (column \#1), using $\hat{p}_{2}$ as the probability of an individual success. 
Table 3: Exchange-Rate Changes: Basic Statistics

German Mark

\begin{tabular}{|c|c|c|c|c|c|c|c|c|c|c|}
\hline \multicolumn{11}{|c|}{ Full Sample $(n=760)$} \\
\hline & Mean & Std. Dev. & $\mathrm{m}_{3}$ & $\mathrm{~m}_{4}$ & $\mathrm{App}^{1}$ & Dep $^{2}$ & $\underline{\mathrm{Sm} 1^{\underline{3}}}$ & $\underline{\mathrm{Sm} 2^{4}}$ & $Q(10)^{\frac{5}{5}}$ & $Q^{2}(10)^{6}$ \\
\hline$\Delta S$ & $-0.4 \cdot 10^{-4}$ & $0.8 \cdot 10^{-2}$ & $-0.6^{*}$ & $6.9^{*} *$ & 377 & 371 & 497 & 491 & 10.3 & $41.1^{*}$ \\
\hline$\triangle S A M$ & $-0.2 \cdot 10^{-3}$ & $0.1 \cdot 10^{-1}$ & 0.1 & $4.1 *$ & -- & -- & -- & -- & 15.3 & $73.4 *$ \\
\hline$\triangle S P M$ & $-0.2 \cdot 10^{-3}$ & $0.1 \cdot 10^{-1}$ & -0.1 & $5.1 *$ & -- & -- & -- & -- & 5.5 & $33.9 *$ \\
\hline \multicolumn{11}{|c|}{ Restricted Sample $(n=616)$} \\
\hline & $\underline{\text { Mean }}$ & Std. Dev. & $\mathrm{m}_{3-}$ & $\underline{\mathrm{m}}_{4}$ & $\underline{A p p}^{1}$ & ${\underline{\text { Dep }^{2}}}^{2}$ & $\underline{\mathrm{Sm} 1^{\underline{3}}}$ & $\underline{\mathrm{Sm} 2^{4}}$ & $Q(10)^{\frac{5}{5}}$ & $\underline{Q}^{2}(10)^{6}$ \\
\hline$\Delta S$ & $-0.1 \cdot 10^{-3}$ & $0.8 \cdot 10^{-2}$ & -0.1 & $4.4^{*}$ & 295 & 312 & 398 & 403 & -- & -- \\
\hline$\triangle S A M$ & $-0.5 \cdot 10^{-3}$ & $0.1 \cdot 10^{-1}$ & 0.0 & $4.2 *$ & -- & -- & -- & -- & -- & -- \\
\hline$\triangle S P M$ & $-0.4 \cdot 10^{-3}$ & $0.1 \cdot 10^{-1}$ & 0.0 & $5.3^{*}$ & -- & -- & -- & -- & -- & -- \\
\hline
\end{tabular}

Japanese Yen

Full Sample $(n=760)$

\begin{tabular}{|c|c|c|c|c|c|c|c|c|c|c|}
\hline & $\underline{\text { Mean }}$ & Std. Dev. & $\mathrm{m}_{\underline{3}}$ & $\underline{\mathrm{m}}_{4}$ & $\underline{A p p}^{1}$ & Dep $^{2}$ & $\underline{\mathrm{Sm} 1^{3}}$ & $\underline{\mathrm{Sm} 2}$ & $\underline{Q(10)^{2}}$ & $\mathrm{Q}^{2}(10)^{6}$ \\
\hline & $-0.1 \cdot 10^{-1}$ & 0.6 & $-1.5^{*}$ & $18.8^{*}$ & 388 & 354 & 508 & 411 & 14.8 & 16.6* \\
\hline$S A$ & $-0.8 \cdot 10^{-2}$ & 0.9 & $-0.3 *$ & $6.4^{*}$ & -- & -- & -- & -- & $20.5 *^{7}$ & $133.5^{*}$ \\
\hline CDA & $-0.8 \cdot 10^{-2}$ & 1.0 & 0.0 & $6.0 *$ & -- & -- & -- & -- & 4.1 & $78.9 *$ \\
\hline
\end{tabular}

Restricted Sample $(n=625)$

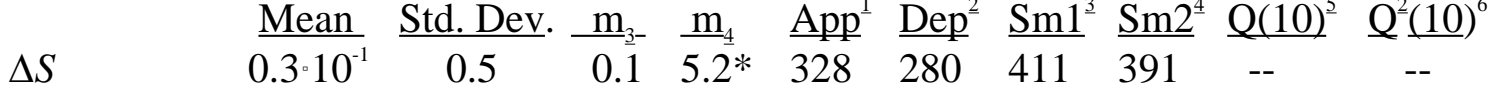

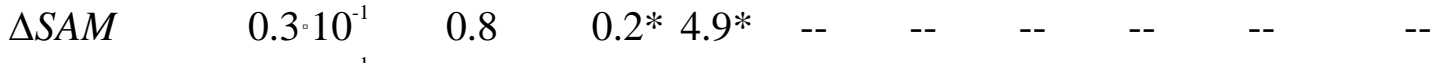

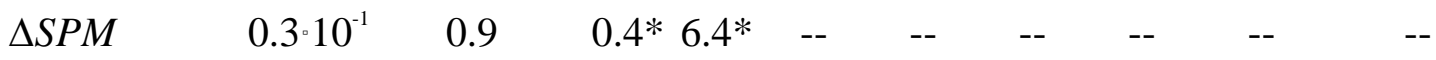

* / ** statistically significant at a 95 percent / 90 percent confidence interval, respectively.

$\Delta S=S P M_{t}-S A M_{t} ; \Delta S A M=S A M_{t}-S A M_{t-1} ; \Delta S P M=S P M_{t}-S P M_{t-1}$

Notes:

1. Number of appreciations for $\Delta S$.

2. Number of depreciations for $\Delta S$.

3. Number of appreciations for $\Delta S$ plus smaller depreciations when comparing $\Delta S$ with $\triangle S A M$.

4. Number of depreciations for $\Delta S$ plus smaller appreciations when comparing $\Delta S$ with $\triangle S A M$.

5. Box-Pierce Portmanteau Test for autocorrelation in exchange-rate changes with 10 lags. Not applicable to the restricted samples.

6. Box-Pierce Portmanteau Test for autocorrelation in squared exchange-rate changes with 10 lags as preliminary test for GARCH. Not applicable to the restricted samples.

7. $\triangle S A M$ for the Japanese yen contains a single significant autocorrelation at lag 6 . 
Table 4: Effect of Individual Variables on the Odds Ratio for Successful U.S. Intervention against German Marks ${ }^{1}$

$\begin{array}{lccccc} & \text { Coefficient } & \text { t-statistic } & \text { Constant } & \text { t-statistic } & \text { LR test }^{2} \\ \text { Intervention Amounts } & & & & & \\ \text { ING } & -0.001 & -0.463 & 0.674 & 2.375 & 0.213 \\ \text { IHATG } & 0.017 & 3.869 & -1.097 & -2.441 & 18.215 \\ \text { BG1 } & -0.169 & -0.389 & 0.604 & 3.109 & 0.150 \\ \text { Special Factors } & & & & & \\ \text { CORDG } & 0.687 & 1.831 & 0.095 & 0.308 & 3.341 \\ \text { FRST } & 0.553 & 1.083 & 0.489 & 2.610 & 1.242 \\ \text { RI } & 0.013 & 0.027 & 0.560 & 1.263 & 0.001 \\ \text { RIA } & -0.373 & -0.956 & 0.836 & 2.518 & 0.933 \\ \text { REPINT } & 0.224 & 0.613 & 0.423 & 1.433 & 0.374 \\ & & & & & \\ \text { Monetary Policy } & & & & & \\ \text { FTAR } & 11.314 & 0.885 & 0.538 & 3.070 & 1.428 \\ \text { EFTAR } & 83.431 & 0.051 & 0.537 & 3.079 & 2.724 \\ \text { T1 } & 0.841 & 0.743 & 0.546 & 3.100 & 0.638 \\ \text { T2 } & 10.973 & 0.060 & 0.537 & 3.079 & 2.724 \\ \text { GMP } & -0.597 & -0.714 & 0.597 & 3.355 & 0.504 \\ \text { YES } & -0.083 & -0.215 & 0.594 & 2.899 & 0.046 \\ & & & & & \\ \text { Other Announcements } & & & & & \\ \text { CPI } & 1.075 & 0.969 & 0.534 & 3.028 & 1.153 \\ \text { UXCPI } & -1.207 & -0.155 & 0.575 & 3.270 & 0.024 \\ \text { EMP } & -0.422 & -0.667 & 0.604 & 3.331 & 0.438 \\ \text { UXEMP } & -1.605 & -0.394 & 0.587 & 3.285 & 0.153 \\ \text { BOT } & 0.556 & 0.666 & 0.542 & 3.049 & 0.478 \\ \text { UXBOT } & 0.197 & 0.457 & 0.555 & 3.147 & 0.224 \\ \text { GNP } & -1.322 & -1.495 & 0.629 & 3.517 & 2.409 \\ \text { UXGNP } & -0.631 & -0.364 & 0.581 & 3.302 & 0.131 \\ \text { NEW } & -0.372 & -0.535 & 0.595 & 3.308 & 0.282\end{array}$

1. Sample period extends from $2 / 18 / 87$ to $2 / 23 / 90$ and includes $n=144$ interventions, of which $W=92$ were successful according to expression (1).

2. Likelihood-ratio test with one degree of freedom. Critical values are $X_{.05}^{2}=3.841$; $\mathrm{X}_{.10}^{2}=2.706$. 
Table 5: Effect of Individual Variables on the Odds Ratio for Successful U.S. Intervention against Japanese Yen ${ }^{1}$

\begin{tabular}{|c|c|c|c|c|c|}
\hline & Coefficient & t-statistic & Constant & $\begin{array}{c}\mathrm{t}- \\
\text { statistic }\end{array}$ & LR test ${ }^{2}$ \\
\hline \multicolumn{6}{|c|}{ Intervention Amounts } \\
\hline INJ & 0.000 & 0.072 & 1.071 & 3.440 & 0.005 \\
\hline IHATJ & 0.006 & 1.825 & 0.629 & 2.068 & 3.716 \\
\hline $\mathrm{BJ} 1$ & 0.103 & 0.168 & 1.076 & 5.090 & 0.029 \\
\hline \multicolumn{6}{|c|}{ Special Factors } \\
\hline CORDJ & 1.226 & 2.484 & 0.095 & 0.218 & 5.972 \\
\hline FRST & 0.012 & 0.023 & 1.087 & 4.972 & 0.001 \\
\hline RI & -0.088 & -0.158 & 1.163 & 2.270 & 0.025 \\
\hline RIA & -0.057 & -0.143 & 1.122 & 3.647 & 0.020 \\
\hline REPINT & 0.222 & 0.557 & 0.965 & 3.285 & 0.310 \\
\hline \multicolumn{6}{|c|}{ Monetary Policy } \\
\hline FTAR & 153.46 & 0.066 & 1.048 & 5.260 & 2.362 \\
\hline EFTAR & 75.385 & 0.058 & 1.069 & 5.377 & 1.171 \\
\hline $\mathrm{T} 1$ & 10.462 & 0.066 & 1.048 & 5.260 & 2.362 \\
\hline $\mathrm{T} 2$ & 9.442 & 0.070 & 1.069 & 5.377 & 1.171 \\
\hline JMP & 0.377 & 0.816 & 0.799 & 1.989 & 0.649 \\
\hline YES & 0.143 & 0.345 & 1.036 & 4.175 & 0.120 \\
\hline \multicolumn{6}{|c|}{ Other Announcements } \\
\hline CPI & 11.494 & 0.058 & 1.017 & 5.081 & 4.190 \\
\hline UXCPI & 110.23 & 0.060 & 1.028 & 5.142 & 3.575 \\
\hline EMP & 0.309 & 0.271 & 1.078 & 5.350 & 0.078 \\
\hline UXEMP & 4.726 & 0.526 & 1.069 & 5.323 & 0.332 \\
\hline BOT & 11.494 & 0.058 & 1.017 & 5.081 & 4.190 \\
\hline UXBOT & 46.921 & 0.052 & 1.017 & 5.081 & 4.190 \\
\hline GNP & 0.308 & 0.271 & 1.078 & 5.350 & 0.078 \\
\hline UXGNP & 1.658 & 0.593 & 1.068 & 5.353 & 0.598 \\
\hline NEW & -0.310 & -0.486 & 1.121 & 5.330 & 0.229 \\
\hline
\end{tabular}

1. Sample period extends from $2 / 18 / 87$ to $2 / 23 / 90$ and includes $n=135$ interventions, of which $W=101$ were successful according to expression (1).

2. Likelihood-ratio test with one degree of freedom. Critical values are $X_{.05}^{2}=3.841$; $\mathrm{X}_{.10}^{2}=2.706$. 
Table 6: Test of the Joint Significance of Variables on the Odds Ratio for Successful U.S. Intervention against German Marks ${ }^{1}$

$\begin{array}{lccc} & \begin{array}{c}\text { Log } \\ \text { Likelihood }\end{array} & \text { LR test }^{2} & \text { LR test }^{3} \\ \text { CORDG } & -92.514 & 3.341^{*} & -- \\ \text { plus } \text { T2 } & -91.094 & 6.180^{*} & 2.84^{* *} \\ \text { plus } \text { FRST } & -91.538 & 5.291^{* *} & 1.95 \\ \text { plus } \text { REPINT } & -92.441 & 3.485 & 0.15 \\ \text { plus } \text { GMP } & -92.281 & 3.807 & 0.47 \\ \text { plus } \text { YES } & -92.481 & 3.406 & 0.07 \\ \text { plus } \text { IHAT } & -83.114 & 22.139^{*} & 18.80^{*} \\ & & & \\ \text { CORDG, IHATG } & -83.114 & 22.139^{*} & -- \\ \text { plus } \text { T2 } & -81.765 & 24.837^{*} & 2.70 \\ \text { plus } \text { FRST } & -82.412 & 23.543^{*} & 1.40 \\ \text { plus } \text { REPINT } & -83.072 & 22.224^{*} & 0.08 \\ \text { plus } \text { GMP } & -82.998 & 22.373^{*} & 0.23 \\ \text { plus } \text { YES } & -83.064 & 22.240^{*} & 0.10 \\ & & & \\ \text { CORDG, IHATG, } \text { T2 } & -81.765 & 24.837^{*} & -- \\ \text { plus } \text { FRST } & -81.325 & 25.718^{*} & 0.88 \\ \text { plus } \text { REPINT } & -81.679 & 25.010^{*} & 0.17 \\ \text { plus } \text { GMP } & -81.667 & 25.033^{*} & 0.20 \\ \text { plus } \text { YES } & -81.706 & 24.955^{*} & 0.12 \\ & & & \\ \text { CORDG, IHATG, } & & & -- \\ \text { GMP } & -82.998 & 22.373^{*} & 1.42 \\ \text { plus } \text { FRST } & -82.286 & 23.795^{*} & 0.10 \\ \text { plus } \text { REPINT } & -82.943 & 22.482^{*} & 2.66 \\ \text { plus } \text { T2 } & -81.667 & 25.033^{*} & 0.10 \\ \text { plus } \text { YES } & -82.950 & 22.468^{*} & \end{array}$

1. Sample period extends from $2 / 18 / 87$ to $2 / 23 / 90$ and includes $n=144$ interventions, of which $W=92$ were successful according to expression (1).

2. Likelihood-ratio test compares the log likelihood function with all variables to the log likelihood with only the constant.

3. Likelihood ratio tests the significance of adding a variable to that/those listed at the top of each block.

* significant at the 95 percent confidence level.

** significant at the 90 percent confidence level. 
Table 7: Test of the Joint Significance of Variables on the Odds Ratio for Successful U.S. Intervention against Japanese Yen ${ }^{1}$

$\begin{array}{lccc} & \text { Log Likelihood } & \text { LR test } & \\ \text { CORDJ } & -73.20 & 5.97^{*} & \text { LR test } \\ \text { plus } \text { T2 } & -72.30 & 7.79^{*} & -- \\ \text { plus } \text { FRST } & -73.14 & 6.09^{*} & 1.80 \\ \text { plus } \text { REPINT } & -73.17 & 6.03^{*} & 0.12 \\ \text { plus JMP } & -72.91 & 6.55^{*} & 0.06 \\ \text { plus } \text { YES } & -72.86 & 6.65^{*} & 0.58 \\ \text { plus } \text { IHATJ } & -71.61 & 9.16^{*} & 0.80 \\ & & & 3.18^{* *} \\ \text { CORDJ, IHATJ } & -71.61 & 9.16^{*} & \\ \text { plus } \text { FRST } & -71.48 & 9.42^{*} & -- \\ \text { plus } \text { REPINT } & -71.53 & 9.32^{*} & 0.26 \\ \text { plus JMP } & -71.27 & 9.84^{*} & 0.16 \\ \text { plus } \text { YES } & -71.19 & 9.84^{*} & 0.68 \\ \text { plus } \text { T2 } & -70.63 & 11.12^{*} & 0.84 \\ & & & 1.96 \\ \text { CORDJ, IHATJ, T2 } & -70.63 & 11.12^{*} & \\ \text { plus } \text { FRST } & -70.51 & 11.36^{*} & -- \\ \text { plus } \text { REPINT } & -70.56 & 11.25^{*} & 0.24 \\ \text { plus JMP } & -70.24 & 11.90^{*} & 0.14 \\ \text { plus } \text { YES } & -70.33 & 11.72^{*} & 0.78 \\ & & & 0.60 \\ \text { CORDJ, IHATJ, JMP } & -70.24 & 11.90^{*} & -- \\ \text { plus } \text { FRST } & -71.13 & 10.11^{*} & 0.28 \\ \text { plus } \text { REPINT } & -71.20 & 9.99^{*} & 0.14 \\ \text { plus } \text { T2 } & -70.24 & 11.90^{*} & 2.06 \\ \text { plus } \text { YES } & -70.88 & 10.62^{*} & 0.78 \\ & & & \end{array}$

1. Sample period extends from $2 / 18 / 87$ to $2 / 23 / 90$ and includes $n=135$ interventions, of which $W=101$ were successful according to expression (1).

2. Likelihood-ratio test compares the log likelihood function with all variables to the $\log$ likelihood with only the constant.

3. Likelihood ratio tests the significance of adding a variable to that/those listed at the top of each block.

* significant at the 95 percent confidence level.

** significant at the 90 percent confidence level. 
Table 8: Estimated Conditional Probabilities of Successful U.S. Intervention against German Marks

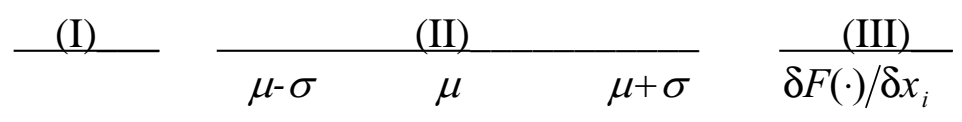

Coordinate Intervention

$\begin{array}{llllll}\text { CORDG }=1 & 0.686 & 0.514 & 0.716 & 0.857 & 0.004 \\ \text { CORDG }=0 & 0.524 & 0.324 & 0.532 & 0.730 & 0.005\end{array}$

Unconditional Probability of Success: [92 successes / 144 interventions] $=0.639$

Notes:

(I) Based on: $L=0.095+0.687(\mathrm{CORDG}) ; \quad L L=-92.514$
(0.31) (1.83)
$L L(0)=-94.184$.

(II) Based on: $L=-1.694+0.794($ CORDG $)+0.019$ (IHATG); $L L=-83.11$;

$$
(-3.06)(1.973) \quad(3.93) \quad L L(0)=-94.18 .
$$

(III) Derivative of the logistic cumulative density function with respect to IHATG, evaluated using the equation in (II). 
Table 9: Estimated Conditional Probabilities of Successful U.S. Intervention against Japanese Yen

$$
\stackrel{(\mathrm{I})}{\frac{(\mathrm{II})}{\mu-\sigma} \quad \mu+\sigma} \quad \frac{(\mathrm{III})}{\delta F(\cdot) / \delta x_{i}}
$$

Coordinate Intervention

$\begin{array}{llllll}\text { CORDJ }=1 & 0.789 & 0.722 & 0.795 & 0.853 & 0.001 \\ \text { CORDJ }=0 & 0.524 & 0.444 & 0.543 & 0.639 & 0.001\end{array}$

Unconditional Probability of Success: [101 successes / 135 interventions $]=0.748$

Notes:

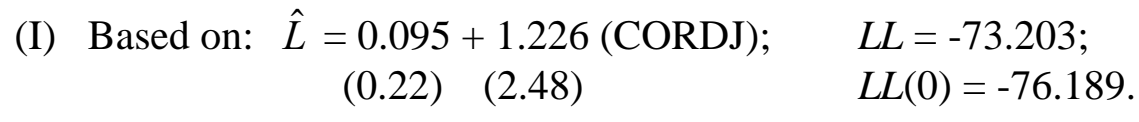

(II) Based on: $\hat{L}=-0.307+1.182($ CORDJ $)+0.005($ IHATJ $) ; \quad L L=-71.611$;

$$
(-0.62) \quad(2.37) \quad(1.70) \quad L L(0)=-76.189 .
$$

(III) Derivative of the logistic cumulative density function with respect to IHATJ, evaluated using the equation in (II). 
Appendix:

Central-Bank Reaction Function

Empirical studies of intervention must confront the simultaneous nature of intervention and exchange-rate changes. Researchers, using high-frequency data, often opt for lagging intervention one period; however, this may create a specification bias. To deal with the simultaneity problem, I estimate a U.S. intervention reaction function and generate the predicted values as instruments for intervention.

\section{Specification}

Intervention to smooth exchange-rate movements could take a continuum of values, depending on the size of day-to-day exchange-rate movements. Instead, one observes episodic interventions only under certain market conditions that occur at discrete intervals. That is, intervention data are incidentally truncated. To construct an unbiased reaction function, I 1) estimate a probit model for the decision to intervene and calculate the inverse Mills ratio, and 2) estimate a separate equation for the amount of intervention, using the inverse Mills ratio to correct for sample selection bias (see Greene [1993], pp. 706-714).

Equation (A1) describes the decision to intervene:

$$
\text { (A1) } Z_{t}^{*}=\mathbf{V}_{\mathbf{t}} \mathbf{a}+u_{t}
$$

and equation $\mathrm{A} 2$ describes the amount of intervention:

$$
\text { (A2) } y_{t}=\mathbf{W}_{\mathbf{t}} \mathbf{g}+\varepsilon_{t}
$$

where $y_{t}$ is observed only when $Z_{t}^{*}>0$, and where

$$
\left(u_{t}, \varepsilon_{t}\right) \sim \text { bivariate normal }\left[0,0, \sigma_{\mu}^{2}, \sigma_{\varepsilon}^{2}, \rho\right]
$$


The expected value of $y$ conditioned on intervention actually taking place is

$$
\begin{aligned}
E\left[y_{t} \mid y_{t} \text { is observed }\right] & =E\left[y_{t} \mid Z_{t}^{*}>0\right] \\
& =\mathbf{W}_{\mathbf{t}} \mathbf{g}+E\left[\varepsilon_{t} \mid u_{t}>\mathbf{V}_{\mathbf{t}} \mathbf{a}\right] \\
& =\mathbf{W}_{\mathbf{t}} \mathbf{g}+\rho \sigma_{\varepsilon} \sigma_{u}\left[\phi\left(\mathbf{V}_{\mathbf{t}} \mathbf{a}\right) / \Phi\left(\mathbf{V}_{\mathbf{t}} \mathbf{a}\right)\right] .
\end{aligned}
$$

The bracketed term on the right-hand side of the final expression in (A3) is the Mills ratio. This term is derived from the conditional probability theorem. $\phi(\cdot)$ is the normal density function, and $\Phi(\cdot)$ is the cumulative normal density function.

\section{Estimation}

A least squares regression of (A2) produces inconsistent estimates of the parameters in $\mathbf{g}$. Introducing the Mills ratio takes account of the sample selection bias. The selection variable $Z *$ is not observed; we know only that intervention has taken place $\left(Z^{*}>0\right)$ or has not taken place $\left(Z^{*}=0\right)$. Because $Z^{*}$ has no scale, we must also assume that $\sigma_{u}=1$. The two-step procedure described in Heckman (1979) gives consistent estimates of the parameters in (A3), but a maximum-likelihood technique offers more efficient estimates than does the Heckman procedure.

I specify separate models for U.S. intervention against German marks and Japanese yen. I describe the decision to intervene as a function of deviations from a 10day moving average of the exchange rate, MOVAG, and a 10-day rolling standard deviation, SIG. The former captures deviations from recent trends; the latter serves as a broader measure of exchange-rate volatility (market disorder). 
I depict the amount of intervention as a function of recent exchange-rate changes and the FOMC's expressed concern about dollar exchange rates. While deviations from trend and volatility may trigger intervention, the size of the most recent exchange-rate change may influence the amount of the transaction. I include $\triangle S A M_{t}^{--}$the day-to-day change in the morning quotation--expecting large changes in this rate to trigger big interventions. I rely on $D_{u}$ (the variable for FOMC concern about the dollar) for identification.

Furlong (1989) suggests that the order in which the FOMC specifies its policy objectives in the last paragraph of its domestic policy directive indicates that objective's relative importance to the Committee's recent monetary policy decisions. During my sample period, the specified policy objectives always consist of monetary aggregates, real economic conditions, inflation, exchange-market conditions, and domestic financial market conditions. We include a dummy variable $D_{u}$ that equals one between FOMC meetings at which the Committee mentioned exchange-market conditions first or second in the domestic policy directive.

Table A1 presents estimates of the reaction functions for U.S. intervention against German marks and Japanese yen. All coefficients are statistically significant and have the expected sign except $\rho(\varepsilon, \mu)$ in the German mark model and $\triangle S A M_{t}$ in the Japanese yen model. The predicted values for intervention from these estimated equations (IHATG and IHATJ) are instruments for intervention in the logit equations that appear in the body of this paper. 
Table A1:

Estimates of U.S. Intervention Reaction Functions

Using Sample Selection Techniques

Equation (A1)

MOVAVG

SIGMA

Constant

Equation (A2)

$\triangle S A M_{t}$

$D_{U}$

Constant

$\sigma_{\varepsilon}$

$\rho(\varepsilon, \mu)$

Log likelihood

\section{German Mark} Coefficient t-statistic

$9.23 \quad 1.87$

$40.05 \quad 3.76$

$-1.66-12.11$

$\begin{array}{rr}-3016.00 & -4.04 \\ 166.48 & 2.05 \\ -105.92 & -2.14 \\ 152.23 & 20.66 \\ 0.07 & 0.28\end{array}$

$-1268.10$
Japanese Yen

\begin{tabular}{|c|c|}
\hline Coefficient & t-statistic \\
\hline 0.15 & 3.26 \\
\hline 0.49 & 5.22 \\
\hline-1.76 & -15.20 \\
\hline
\end{tabular}

$\begin{array}{rr}-13.20 & -1.46 \\ 201.51 & 5.46 \\ -289.84 & -6.27 \\ 212.93 & 9.53 \\ 0.82 & 10.24\end{array}$

1178.60 


\section{References}

Adams, Donald B. and Dale W. Henderson, "Definition and Measurement of Exchange Market Intervention," Board of Governors of the Federal Reserve System, Staff Studies, No. 126, September 1983.

Almekinders, Geert J. and Sylvester C. W. Eijffinger, "Empirical Evidence on Foreign Exchange Market Intervention: Where Do We Stand?" Weltwirtschaftliches Archiv, 127 (December 1991), pp. 645-677.

and "Daily Bundesbank and Federal Reserve Intervention and the Conditional Variance Tale in DM/\$-Returns," Board of Governors of the Federal Reserve System, International Finance Discussion Papers, No. 438, December 1992.

Baillie, Richard and Patrick McMahon, The Foreign Exchange Market: Theory and Econometric Evidence. New York: Cambridge University Press, 1989.

Bonser-Neal, Catherine and Glenn Tanner, "Central Bank Intervention and the Volatility of Foreign Exchange Rates: Evidence from the Options Market," Journal of International Money and Finance (forthcoming).

Dominguez, Kathryn Mary, "Market Responses to Coordinated Central Bank Intervention," Carnegie-Rochester Conference Series on Public Policy, vol. 32 (1990), pp. 121-164.

and Jeffrey A. Frankel, Does Foreign Exchange Intervention Work?

Washington, D.C.: Institute for International Economics, 1993.

Edison, Hali J., "The Effectiveness of Central-Bank Intervention: A Survey of the Literature after 1982," Princeton University, Special Papers in Economics, No. 18, July 1993.

Funabashi, Yoichi, Managing the Dollar: From the Plaza to the Louvre. Washington, D.C.: Institute for International Economics, 1988.

Furlong, Frederick. "International Dimensions of U.S. Economic Policy in the 1980s," Federal Reserve Bank of San Francisco, Economic Review (Spring 1989), pp. 3-13.

Ghosh, Atish R., "Is It Signaling? Exchange Intervention and the Dollar-Deutschemark Rate," Journal of International Economics, vol. 32 (May 1992), pp. 201-220.

Goodhart, Charles and Thomas Hesse, "Central Bank Forex Intervention Assessed in Continuous Time," Journal of International Money and Finance, vol. 12 (1993), 
pp. 368-389.

Greene, William H., Econometric Analysis, 2d ed. New York: MacMillian Publishing, 1993.

Heckman, J., "Sample Selection Bias as a Specification Error," Econometrica, vol. 47 (1979), pp. 153-161.

Humpage, Owen F., "Intervention and the Dollar's Decline," Federal Reserve Bank of Cleveland, Economic Review, vol. 24, no. 2 (1988 Quarter 2), pp. 2-17.

Hung, Juann H., "Assessing the Effect of Sterilized U.S. Foreign Exchange Intervention: A Noise Trading Perspective," Federal Reserve Bank of New York, unpublished manuscript, January 1992.

Judge, George et al., Introduction to the Theory and Practice of Econometrics, $2 \mathrm{~d}$ ed. New York: John Wiley \& Sons, 1988.

Loopesko, Bonnie E., "Relationships among Exchange Rates, Intervention, and Interest Rates: An Empirical Investigation," Journal of International Money and Finance, vol. 3 (December 1984), pp. 257-277.

Neumann, Manfred J.M. and Jurgen von Hagen, "Monetary Policy in Germany," in Michele Fratianni and Dominik Salvatore, eds., Handbook on Monetary Policy. Westport, Conn.: Greenwood Press, 1991.

Osterberg, William P. and Rebecca Wetmore Humes, "The Inaccuracy of Newspaper Reports of U.S. Foreign Exchange Intervention," Federal Reserve Bank of Cleveland, Economic Review, vol. 29, no. 4 (1993 Quarter 4), pp. 25-33.

Sellon, Gordon H., Jr., “Measuring Monetary Policy,” Federal Reserve Bank of Kansas City, Working Paper RWP94-12, December 1994.

Smith, Ralph W. and Brian F. Madigan, "Exchange Market Management and Monetary Policy in the United States," in Exchange Market and Intervention and Monetary Policy. Basle: Bank for International Settlements, 1988.

Watanabe, Tsutomu, "The Signaling Effect of Foreign Exchange Intervention: The Case of Japan," in Reuven Glick and Michael M. Hutichson, eds., Exchange Rate Policy and Interdependence. Cambridge: Cambridge University Press, 1994, pp. 258-286. 
FIGURE 1: U.S. INTERVENTION AND THE GERMAN MARK

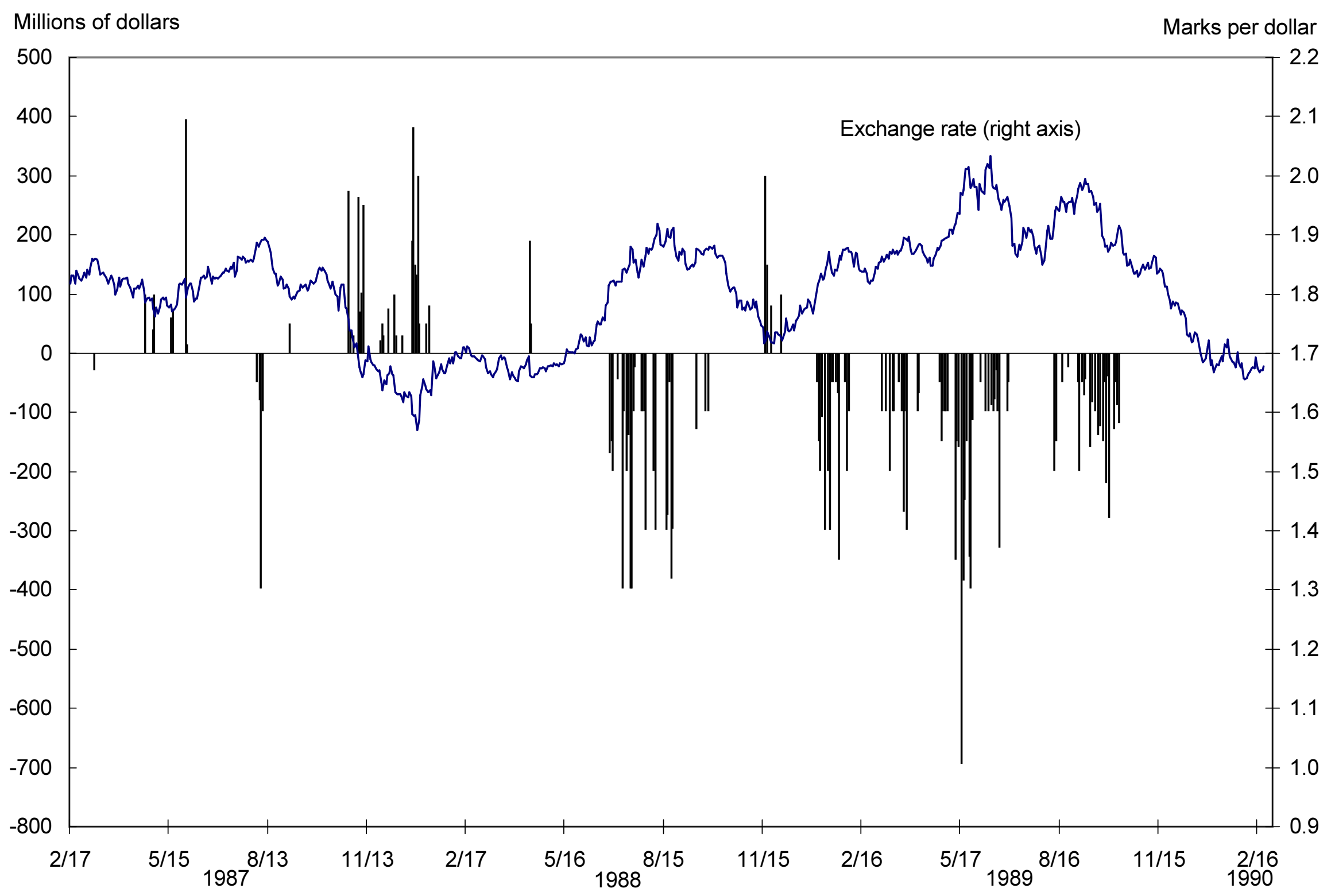

Note: Positive (negative) interventions are mark sales (purchases).

Sources: Board of Governors of the Federal Reserve System; and Federal Reserve Bank of New York. 


\section{FIGURE 2: U.S. INTERVENTION AND THE JAPANESE YEN}

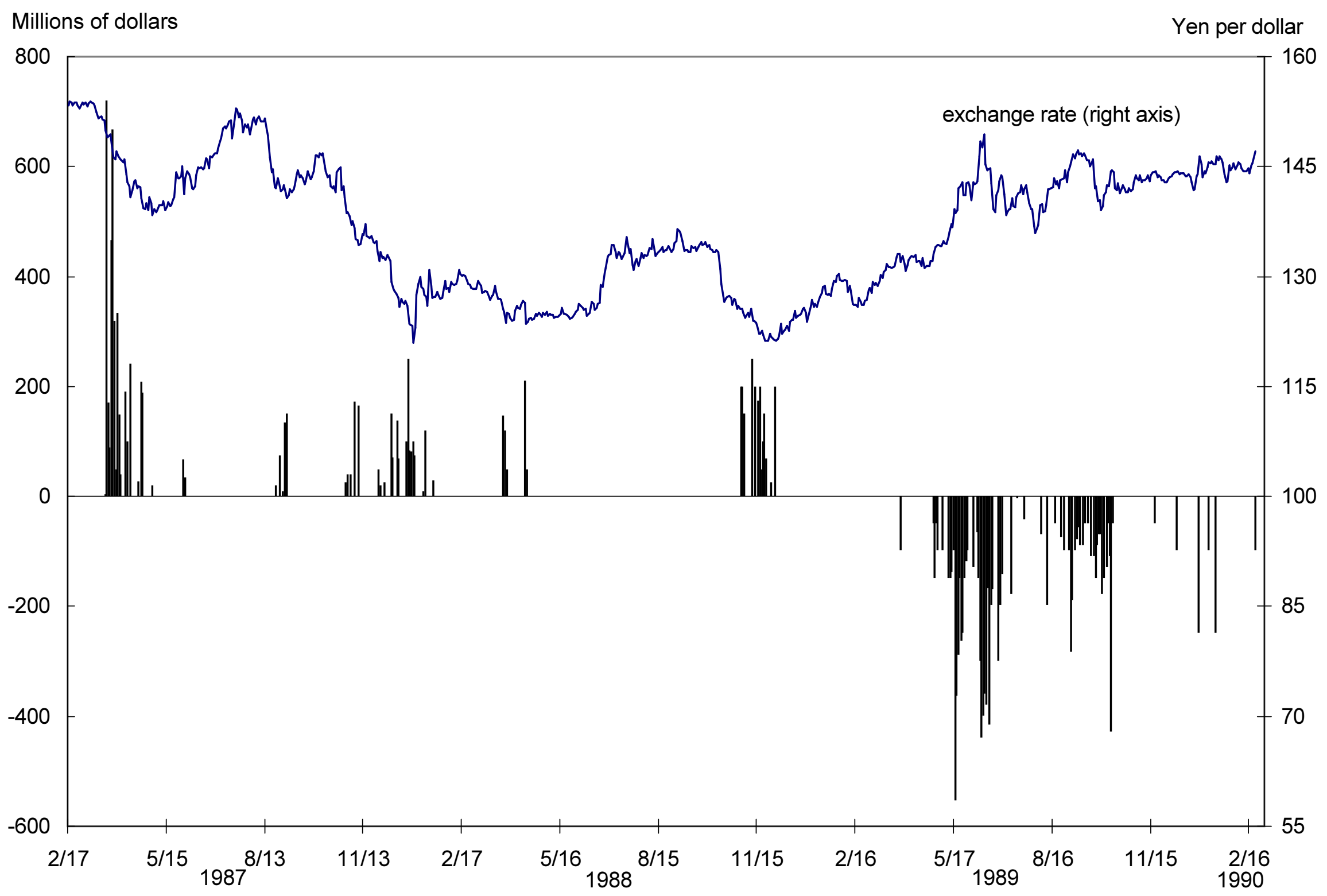

Note: Positive (negative) interventions are yen sales (purchases).

Sources: Board of Governors of the Federal Reserve System; and Federal Reserve Bank of New York. 
FIGURE 3: FEDERAL FUNDS RATE TARGETS

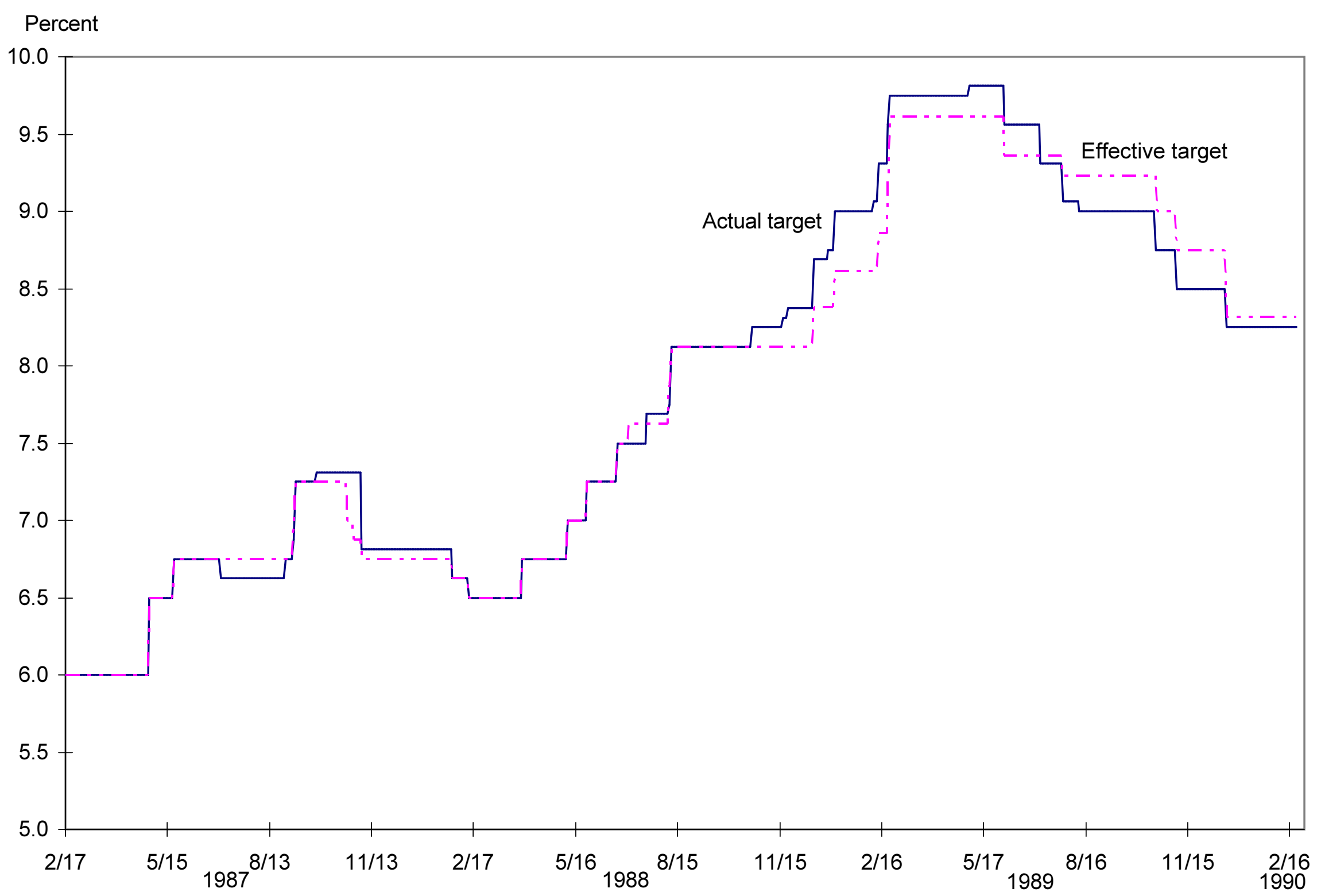

